\title{
Uma investigação das concepções de professores acerca da noção de equação num grupo de formação continuada
}

\author{
Etienne Lautenschlager \\ Programa de Pós Graduação em Neurociência e Cognição, UFABC \\ 09210-170, Santo André, SP \\ E-mail: 1.etienne@ufabc.edu.br
}

\author{
Alessandro Jacques Ribeiro \\ Universidade Federal do ABC - CMCC \\ 09210-170, Santo André, SP \\ E-mail: alessandro.ribeiro@ufabc.edu.br
}

\begin{abstract}
Resumo: No presente trabalho apresentamos e discutimos as zonas de um perfil conceitual de equação presentes nas concepções de um grupo de professores de matemática participante de um curso de formação continuada. Para esta discussão, desenvolvemos um curso de formação continuada que priorizou o estudo, a análise e a discussão dos diferentes significados do conceito de equação, fundamentada na tese de doutoramento de um dos autores intitulada: "Equação e seus Multisignificados no Ensino de Matemática: contribuições de um estudo epistemológico". O conjunto desses significados recebeu o nome de Multisignificados de Equação. Partindo do pressuposto de que o conceito de equação é polissêmico, foram elaboradas algumas zonas preliminares de um perfil conceitual de equação: pragmática, geométrica, estrutural, processual e aplicacional. Dentre as conclusões podemos perceber que a maior parte dos registros analisado, a priori, parece privilegiar as zonas pragmática, e aplicacional. Assim, apontamos algumas reflexões sobre a contribuição que uma abordagem baseada em perfis conceituais de equação, em ambientes de formação continuada de professores, poderá trazer ao ensino e a aprendizagem de matemática, mais especificamente ao ensino da álgebra.
\end{abstract}

\section{Introdução}

Este trabalho apresenta, analisa e caracteriza as zonas de um perfil conceitual de equação presentes nas atividades elaboradas pelos professores de matemática participantes de um curso de formação continuada, para o ensino das equações, destinadas a uma turma do $7^{\circ}$ ano do Ensino Fundamental. As análise e reflexões aqui apresentadas estão fundamentadas no trabalho de Ribeiro (2013), no qual, por intermédio do desenvolvimento de um estudo teórico identificou e categorizou algumas zonas que compõem um perfil conceitual de equação.

Iniciaremos apresentando algumas pesquisas em Educação Algébrica que contribuíram para delinear os rumos deste trabalho. A seguir, apresentaremos as zonas de um perfil conceitual de equação conforme consta em Ribeiro (2013). Finalizaremos, exibindo e analisando as diferentes zonas de um perfil conceitual de equação evidenciadas nos relatos dos professores. Também apresentaremos as considerações e as reflexões finais já que pretendemos apontar algumas implicações para o ensino de matemática, bem como discutir os encaminhamentos que estão sendo levados a cabo como desdobramentos das reflexões aqui postas.

A escolha do presente tema justifica-se pela constatação das dificuldades encontradas pelos alunos dos diferentes níveis de ensino e dos professores em proporem atividades significativas ao ensino da Álgebra, extrapolando a idéia do ensino de álgebra aos processos algorítmicos de letras que substituem números, ou seja, o entendimento de que álgebra é que o "simples cálculo com letras" (LINS e GIMENEZ, 1997).

Nesse sentido, merece destaque a posição de Doerr (2004) que aponta o fato da emergência do desenvolvimento de pesquisas que tenham a preocupação de investigar os conhecimentos do professor de matemática que ensina Álgebra. A autora ressalta ainda em seu trabalho "a carência 
de um corpo substancial de pesquisas sobre o conhecimento e a prática do professor no ensino de Álgebra" (DOERR, 2004, p. 268).

No que concerne ao foco do ensino e aprendizagem da Álgebra, diversas são as pesquisas na área de Educação Algébrica. Algumas delas, como Araújo (1999) apresenta conclusões muito importantes e contributivas ao constatar, em sua pesquisa, que nos cursos de formação dos professores, geralmente, "não existe preocupação de refletir sobre a formação do pensamento algébrico, para que os futuros professores possam ter uma prática mais significativa, que garanta uma aprendizagem real da Álgebra" (ARAÚJO, 1999, p.13).

Ribeiro (2001) também após realizar a análise dos resultados do Sistema de Avaliação do Rendimento Escolar do Estado de São Paulo, edição de 1997, concluiu que a Álgebra representa um problema no ensino e aprendizagem de Matemática, pois os alunos analisados apresentaram dificuldades em resolver questões básicas com equações de $1^{\circ}$ grau. $\mathrm{O}$ autor também detecta a grande diferença que faz o tipo de ensino e a postura empregada pelo professor em sala de aula, no resultado do desempenho dos alunos e acredita ser importante os cursos de capacitação em ensino da Álgebra para os professores, nos quais pudessem ser oferecidas oportunidades para estudo e discussão de diferentes abordagens que pudessem ser utilizadas em sala de aula, no ensino da Álgebra.

Tais pesquisas nos mostram um breve panorama sobre as dificuldades e limitações que alunos e professores têm quando se deparam com situações que envolvem o estudo da álgebra.

Dando continuidade, apresentaremos a pesquisa de Barbosa, (2009) por ter preocupação semelhante à nossa, no que se refere à concepção de equação dos professores de matemática.

Barbosa (2009), em sua dissertação de mestrado, teve como objetivo identificar como os diferentes significados de equação, categorizados por Ribeiro (2007), se manifestavam nas concepções de professores de Matemática.

$\mathrm{Na}$ pesquisa de Barbosa (2009) constatamos que os significados de equação que apareceram com maior frequência entre os futuros professores e professores pesquisados foram o processual-tecnicista (Ribeiro, 2007), em que a equação é concebida como a sua própria resolução, os métodos e técnicas que são utilizadas para resolvê-la e o intuitivo-pragmático (Ribeiro, 2007) em que a noção de equação é concebida como uma noção intuitiva, ligada à ideia de igualdade entre duas quantidades.

"Percebemos em nossa pesquisa que a presença de diferentes significados de equação na imagem de conceito dos professores ainda é bastante limitada, estando muito vinculada à ideia do princípio de equivalência e principalmente a técnicas de resolução e à existência de incógnita". (BARBOSA, 2009, p. 177)

Sendo assim, com a pretensão de contribuir com os estudos e discussões em relação ao ensino da Álgebra, reiteramos que nosso objetivo é apresentar, analisar e reconhecer as zonas de um perfil conceitual de equação, elaboradas por Ribeiro (2013), presentes no repertório dos professores que ensinam Matemática num ambiente de Formação Continuada.

\section{Zonas de um perfil conceitual de equação}

Passaremos a apresentar as zonas identificadas e categorizadas por Ribeiro (2013) resultante das análises dos dados produzidos nos trabalhos de Ribeiro (2007), de Barbosa (2009) e de Dorigo (2010). Trata-se de três trabalhos de naturezas diversas, porém complementares. Ribeiro (2007) desenvolveu um trabalho de caráter teórico no qual buscou identificar diferentes significados do conceito de equação por meio de estudos epistemológico e didático. Em sua tese, o autor nomeia as diferentes formas de se conceber e de se tratar o conceito de equação, em cada época histórica, por multisignificados de equação (ver Tabela 1). 
Barbosa (2009) e Dorigo (2010) propuseram-se a investigar se e como os significados identificados na pesquisa de Ribeiro (2007) estão presentes nas concepções de professores e alunos, respectivamente.

\section{Significado}

\begin{tabular}{|c|c|}
\hline Significado & Características \\
\hline Intuitivo - Pragmático & $\begin{array}{l}\text { Equação concebida como noção intuitiva, ligada à ideia de } \\
\text { igualdade entre duas quantidades. Utilização relacionada à } \\
\text { resolução de problema de ordem prática originários de situações } \\
\text { do dia a dia. }\end{array}$ \\
\hline Dedutivo-Geométrico & $\begin{array}{l}\text { Equação concebida como noção ligada às figuras geométricas, } \\
\text { segmentos e curvas. Utilização relacionada às relações } \\
\text { envolvendo cálculos e operações com segmentos, com medida } \\
\text { de lados de figuras geométricas e intersecção de curvas. }\end{array}$ \\
\hline Estrutural - Generalista & $\begin{array}{l}\text { Equação concebida como noção estrutural definida e com } \\
\text { propriedades e características próprias, considerada por si } \\
\text { própria e operando-se sobre ela. Utilização relacionada com a } \\
\text { busca de soluções gerais para uma classe de equações de mesma } \\
\text { natureza. }\end{array}$ \\
\hline Estrutural - Conjuntista & $\begin{array}{l}\text { Equação concebida dentro de uma visão estrutural, porém } \\
\text { diretamente ligada à noção de conjunto. É vista como uma } \\
\text { ferramenta para resolver problemas que envolvam relações } \\
\text { entre conjuntos. }\end{array}$ \\
\hline Processual - Tecnicista & $\begin{array}{l}\text { Equação concebida como a sua própria resolução - os métodos } \\
\text { e técnicas que são utilizadas para resolvê-la. Diferentemente } \\
\text { dos estruturalistas, não enxergam a } \\
\text { equação como um ente matemático. }\end{array}$ \\
\hline Axiomático-Postulacional & $\begin{array}{l}\text { Equação como noção da Matemática que não precisa ser } \\
\text { definida, uma ideia a partir da qual outras ideias, matemáticas e } \\
\text { não matemáticas são construídas. Utilizada no sentido de Noção } \\
\text { Primitiva, como ponto, reta e plano na Geometria Euclidiana. }\end{array}$ \\
\hline
\end{tabular}

Tabela 1: Multisignificados de Equação

Fonte: Adaptado de Ribeiro (2008, p.112)

Os resultados das pesquisas até aqui apresentadas possibilitaram identificar e categorizar algumas zonas de um perfil conceitual de equação. Vale ressaltar que o modelo teórico Perfil Conceitual, desenvolvido por Mortimer (1994), vem sendo largamente empregado no Ensino de Ciências. De acordo com esse modelo, conceitos polissêmicos oportunizam a elaboração de perfis conceituais, os quais são compostos de diferentes zonas, que correspondem a diferentes formas de ver, representar e significar o mundo.

Destarte, assumindo o pressuposto de que o conceito de equação é polissêmico, Ribeiro (2013) identifica e categoriza algumas zonas de um perfil conceitual de equação, utilizando-se de um jogo dialógico entre dados de estudos epistemológicos e ontológicos, o autor apresenta as zonas preliminares de um perfil conceitual (ver tabela 2).

\begin{tabular}{lll} 
Categoria & Breve descrição & Categoria(s) originária(s) \\
\hline \multirow{3}{*}{ Pragmática } & $\begin{array}{l}\text { Equação interpretada a partir de problemas } \\
\text { de ordem prática. Equação admitida como Axiomática. }\end{array}$ \\
& $\begin{array}{l}\text { uma noção primitiva. } \\
\text { Busca pela solução predominantemente } \\
\text { aritmética. }\end{array}$ \\
\hline \multirow{3}{*}{ Geométrica } & $\begin{array}{l}\text { Equação interpretada a partir de problemas } \\
\text { geométricos. Busca pela solução } \\
\text { predominantemente geométrica. }\end{array}$ \\
\hline Estrutural & Equação interpretada a partir de sua Estrutural. Generalista.
\end{tabular}


estrutura interna. Busca pela solução Tecnicista.

predominantemente algébrica.

\begin{tabular}{ll}
\hline \multirow{2}{*}{ Processual } & $\begin{array}{l}\text { Equação interpretada a partir de processos Processual. Tecnicista. } \\
\text { de resolução. Busca pela solução Intuitiva. } \\
\text { aritmética ou algébrica. }\end{array}$ \\
\hline \multirow{2}{*}{ Aplicacional } & $\begin{array}{l}\text { Equação interpretada a partir de suas Pragmática. Conjuntista. } \\
\text { aplicações. Busca pela solução aritmética Intuitiva. } \\
\text { ou algébrica. }\end{array}$
\end{tabular}

Tabela 2: Zonas de um perfil conceitual de equação

Fonte: RIBEIRO (2013, p.63)

\section{Apresentação e análise de alguns registros dos professores}

Os dados aqui apresentados são resultados, conforme dito acima, de uma formação continuada destinada aos professores de Matemática, com carga horária de 16 horas que foram distribuídas em quatro dias. A formação foi oferecida por uma instituição de ensino superior localizada na região do Alto Tietê - SP, onde se priorizou a realização de estudo, análise e discussão das diferentes concepções de Álgebra, presentes ou não na Proposta Curricular do Estado de São Paulo, sobretudo no que se refere mais especificamente das diferentes formas de ver e de tratar a noção de Equação, constituindo uma oportunidade de estudo e discussão sobre a construção de novos conhecimentos em trabalhos individuais e coletivos.

Num primeiro momento, fizemos um levantamento para investigar as zonas de um perfil conceitual de equação e os conhecimentos dos sujeitos envolvidos no curso sobre os processos de ensino e aprendizagem da equação. Coletamos os dados para este estudo por meio dos seguintes instrumentos: questionários; registros escritos de observações colhidas nas sessões de formação, passando, em seguida, para a apresentação, discussão e estudo das categorias das zonas de um perfil conceitual de equação e finalizando com a análise dos dados e das discussões. Vale ressaltar que a maioria dos professores investigados julgou a equação como o conteúdo mais importante em álgebra.

$\mathrm{Na}$ intenção de ilustrar e de fundamentar a condição acima contemplada, apresentaremos, a seguir, dois momentos de uma mesma situação que foram apresentadas durante a formação.

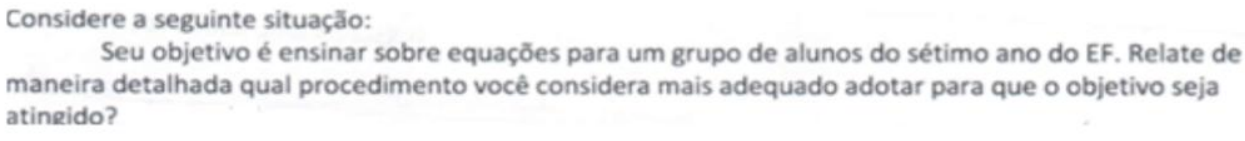

Seu objetivo é ensinar sobre equações para um grupo de alunos do sétimo ano do EF. Relate de maneira detalhada qual procedimento você considera mais adequado adotar para que o objetivo seja atineido?

Figura 1 - Atividade Formação de Professores de Matemática

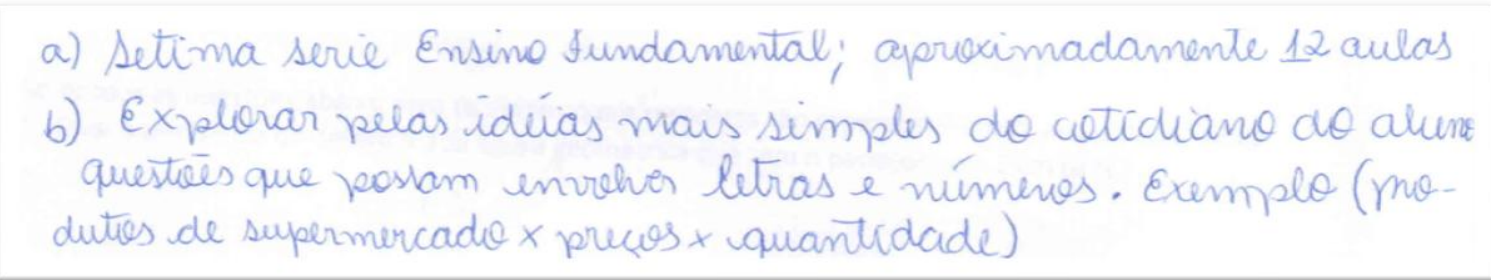

Figura 2 - Resposta obtida do Professor A - primeiro momento 


$$
\begin{aligned}
& \text { * Explicar o uso de equacác no din a din deles } \\
& \text { material. Ntilizar } 0 \text { avácio de om estacionamonto }
\end{aligned}
$$

Figura 3 - Resposta obtida do Professor B - primeiro momento

As figuras 2 e 3 revelam no primeiro momento da formação, onde ainda não foram apresentadas as zonas de um perfil conceitual de equação, que os professores optam em utilizar situações de aprendizagem relacionadas à resolução de problema de ordem prática originários de situações do dia-a-dia, evidenciando as zonas pragmática e aplicacional.

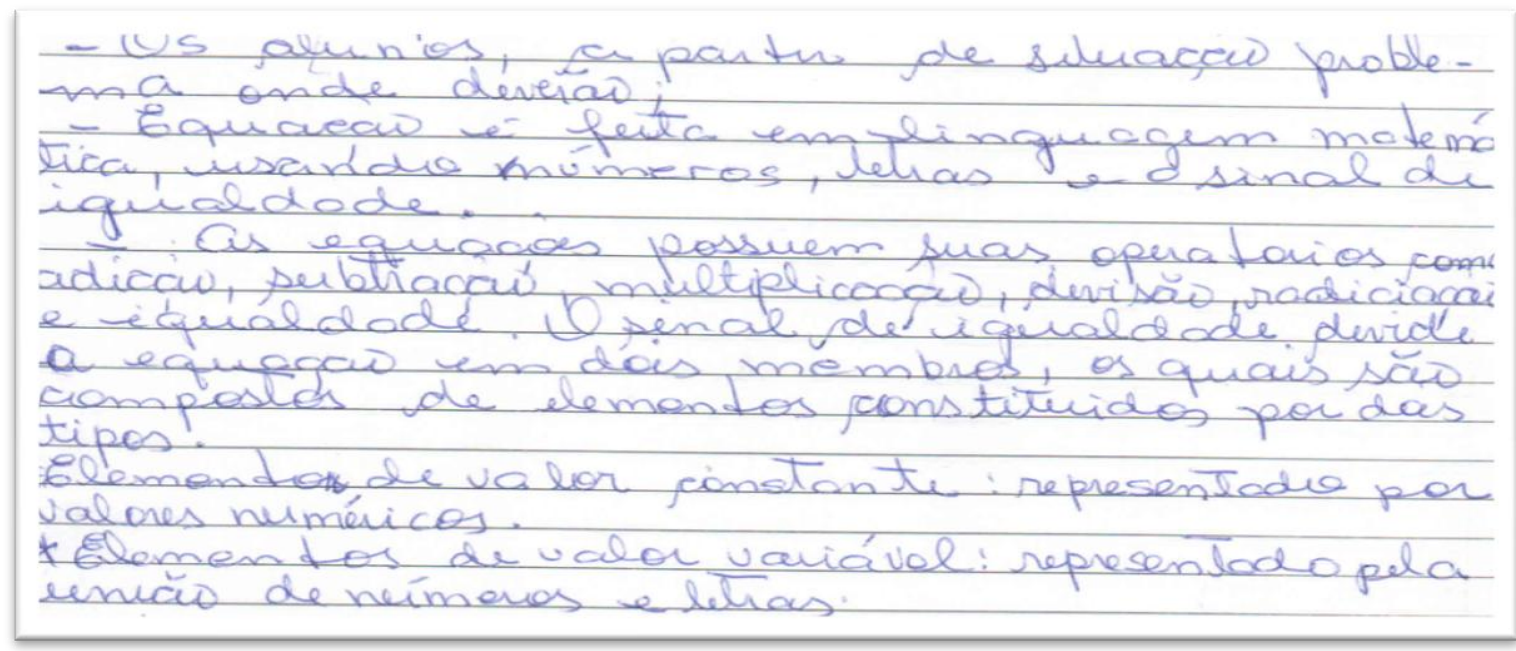

Figura 4 - Resposta obtida do Professor C - após a intervenção

Após realizarmos o estudo e a apresentação das zonas de um perfil conceitual de equação, e solicitarmos novamente aos professores participantes para que refizessem a situação 01 apresentada (ver figura 1) observamos uma maior diversificação das mesmas. Na figura 4 fica evidenciada a noção estrutural definida da equação, com propriedades e características próprias, evidenciando a categoria estrutural que no primeiro momento não havia aparecido em nenhum dos registros realizados pelos professores.

\section{Considerações Finais}

Nestas considerações finais, apresentamos uma síntese das reflexões sobre os dados apresentados. Trazemos, ainda, nosso ponto de vista sobre os princípios que deveriam ser levados em conta para desenvolver um projeto de formação continuada de professores que ensinam Matemática, especialmente quando o objeto de discussão é a equação. Fundamentadas na pesquisa elaborada por Ribeiro (2013), organizamos uma intervenção em um curso de formação para professores que ensinam matemática.

A partir da nossa intervenção, percebemos que os professores procuraram contemplar as diferentes categorias das zonas de um perfil conceitual de equação, apresentando uma maior variedade de atividades e, em decorrência desse fato, também empregaram mais de um significado de equação, tendo o segundo relato revelado uma presença bem variada desses significados.

Tendo em vista a comprovação da importância dessa Formação, em que proporcionamos o estudo de algumas pesquisas, além da troca de experiências e de discussões 
fundamentadas nos estudos realizados pelo grupo, este trabalho conclui pela relevância de promover espaços que favoreçam a discussão e o estudo sobre o tema. Vale ressaltar que, por vezes, tais pesquisas não chegam até o professor por vários fatores, dentre os quais citamos, por exemplo, a falta de tempo para que o docente possa pesquisar. Consideramos que os professores (re)construíram e ampliaram o conceito de equação após a apresentação e discussão das novass zonas para o perfil conceitual de equação.

\section{Referências}

[1] ARAUJO, Elizabeth Adorno de. Influências das habilidades e das atitudes em relação à matemática e à escolha profissional. Tese (Doutorado) - Faculdade de Educação, Universidade Estadual de Campinas, Campinas/SP, 1999.

[2] BARBOSA, Y. O. Multisignificados de equação: uma investigação sobre as concepções de professores de Matemática. 2009. 196 f. Dissertação (Mestrado em Educação Matemática) Universidade Bandeirante de São Paulo, São Paulo, 2009.

[3] DOERR, H. M. (2004). Teacher's Knowledge and Teaching of Al gebra. Stancey, K., Chick. H., Kendal, M. (Eds.) The future of the teaching and learning of algebra: The $12^{\text {th }}$ ICMI Study. (pp. 267-289) New York: Kluwer Academic Publishers

[4] DORIGO, M. Investigando as concepções de equação de um grupo de alunos do ensino médio. 2010. 137 f. Dissertação (Mestrado em Educação Matemática) - Universidade Bandeirante de São Paulo, São Paulo, 2010.

[5] LINS, Romulo Campos e GIMENEZ, Joaquim. Perspectivas em Aritmética e Álgebra para o Século XXI. Campinas, SP: Papirus, 1997

[6] MORTIMER, E. F. Evolução do atomismo em sala de aula: mudanças de perfis conceituais. 1994. 281 f. Tese (Doutorado em Educação) - Faculdade de Educação, Universidade de São Paulo, São Paulo, 1994.

[7] RIBEIRO, A. J. Analisando o desempenho de alunos do Ensino Fundamental em Álgebra, com base em dados do SARESP. Dissertação (Mestrado em Educação Matemática) - Pontifícia Universidade Católica de São Paulo, São Paulo, 2001. 116p

[8] RIBEIRO, A. J. Equação e seus multisignificados no ensino de matemática: contribuições de um estudo epistemológico. 2007. 144 f. Tese (Doutorado em Educação Matemática) - Pontifícia Universidade Católica, São Paulo, 2007.

[9] RIBEIRO, Alessandro Jacques. Elaborando um perfil conceitual de equação: desdobramentos para o ensino e a aprendizagem de Matemática. Ciênc. educ. (Bauru), Bauru , v.19, n.1, 2013 . 